\title{
Student Perceptions of an Introductory Laboratory Course
}

\author{
Jennifer Blue $^{\mathrm{a}}$ and Joshua Jacob ${ }^{\mathrm{b}}$ \\ ${ }^{a}$ Miami University Department of Physics, 133 Culler Hall, Oxford, OH 45056 \\ ${ }^{b} 823$ N. Highland Ave., Apt. 1, Atlanta, GA 30306
}

\begin{abstract}
We surveyed students taking an introductory university physics laboratory course over the summer. These students are science majors, but not physics majors. Eighteen students were interviewed, asked what they thought the purpose of the laboratory course was. Student perceptions of the purpose of the laboratory course and about what they liked and did not like about the course will be shared. These student responses lead to implications for instruction and implications for improving communication among faculty, teaching assistants, and students.
\end{abstract}

Keywords: Physics Education Research, Laboratories, Attitudes

PACS: 01.40.Fk, 01.40Di

\section{INTRODUCTION}

At Miami University, we have been studying the introductory laboratory for a number of years $[1,2,3]$. One of the things we are discussing as a department is the purpose of the laboratory course. As we consider the possibility of moving to a format more like SCALE-UP [4], which would be a substantial change, we should remind ourselves why we have students doing introductory laboratory activities at all.

The American Association of Physics Teachers (AAPT) has a position paper on the goals of the introductory physics laboratory [5]. It identifies five possible goals as:

I. The Art of Experimentation

II. Experimental and Analytical Skills

III. Conceptual Learning

IV. Understanding the Basis of Knowledge in Physics

V. Developing Collaborative Learning Skills

There are some programs, like the ISLE program [6], which state their goals quite explicitly. At Miami University, we have not stated explicit goals for our introductory physics laboratories. As part of the assessment of our current course, we surveyed our students.

\section{METHODS}

The students surveyed were taking our introductory physics laboratory course during the summer. This course is a one-credit course designed as a co-requisite for either a calculus-based or an algebra-based lecture course. Students from both lecture courses take the same laboratory course together, so there is an integration of students at two different levels. The laboratory is fairly traditional, with students filling in a workbook-style laboratory manual as they do activities concerning mechanics, dynamics, conservation laws, oscillations, and waves.

The students surveyed were all majoring in science or in engineering, though none were majoring in physics. Eighteen students were interviewed. The analysis of these interviews is the basis of this paper.

The interview protocol was designed by Joshua Jacob, who at the time was an undergraduate physics major, with the assistance of Jennifer Blue, who advised him in his research project. The questions asked in the interview, with appropriate follow-up were:

- What do you think is the purpose of this laboratory course?

- What is it you like about the labs?

- What do you not like about the labs?

- Again, why do you think we have this course?

For the purposes of this paper, we will concentrate on student responses to the starting and ending questions about the purpose of the introductory laboratory course.

\section{RESULTS}

The responses from the interview transcripts have been categorized into five broad reasons, plus a separate category for students who stated that they did 
not know why the laboratory course was required. These reasons appear in Table 1, below.

TABLE 1. Responses to, "What do you think is the purpose of this laboratory course?" $\mathrm{N}=18$ students

\begin{tabular}{lcc}
\hline \multicolumn{1}{c}{ Reason } & $\begin{array}{c}\text { Number of } \\
\text { Students }\end{array}$ & $\begin{array}{c}\text { Percent of } \\
\text { Students }\end{array}$ \\
\hline Apply Lecture Material & 15 & $83 \%$ \\
Help Understand Physics & 6 & $33 \%$ \\
Get Hands-on Experience & 5 & $28 \%$ \\
Different Kind of Teaching & 2 & $11 \%$ \\
Group Work & 1 & $6 \%$ \\
Don't Know / It's Required & 4 & $22 \%$ \\
\hline
\end{tabular}

Note that the total number of students in the table is more than 18, and the total percent of students giving these responses is more than $100 \%$. This is because most students gave more than one answer.

The responses were categorized according to the first thing the student said when asked the question. The top three reasons students give for requiring a laboratory course are (1) to help them apply the material they saw in lecture, (2) to help them understand the material better, and (3) to get hands-on experience with the material.

\section{Lab Helps Students Understand Physics}

Six students, $33 \%$ of those responding, said that the laboratory course is there to help them understand physics. Some, like Student 18, said, "It would be hard to take lecture without lab. Because a lot of what I learn in lab I apply to the lecture material." Student 18 continued with an example about collisions:

One thing that I recall was when we were doing collisions, elastic and inelastic: in the book, they kind of gave some random examples, which didn't really get the point across. But then in lab what we did, with that air track, we took two frictionless cars on the air track and ran both types of collisions and now I have a concrete picture in my mind every time I thought of what an inelastic collision is and what an elastic collision is.

A few students specifically mentioned thinking about labs during their exams. For example, Student 4 talked about conservation of mechanical energy:

I mean you prove it in lab cause you see that it happens but then you also then have that enforced like oh you can just remember in lab when you're at a test like, oh, ball drops, potential energy kinetic energy stuff like that.
Taking the laboratory course gives students the ability to see, in a concrete way, the physics they have heard about in lecture. Having seen it, they can later visualize it. The students attest that this visualization helps them to understand.

A couple of students mentioned that they found the lecture quite difficult and that they only understood the lecture material after they had laboratory. Student 9 voiced this:

I have a lot better understanding of what we do in class after lab. It's really helpful in the sense that the equations and numbers make sense after I actually work with them in lab .... And also in lecture I am totally confused when it is first presented to me and don't totally understand it so much, and I can go ahead and memorize it, but like I don't understand why everything's happening the way it is. But then when I actually see it, in experiments and stuff, then it actually makes sense to me why it works in lecture.

Even though this student is able to memorize what he or she is told in lecture, sense making comes in the laboratory. For a majority of the students interviewed, this sense making came from applying the physics to new contexts.

\section{Lab Helps Students Apply Physics}

Fifteen students, $83 \%$ of those responding, said that the laboratory course is there to help them apply physics. Not all of them used the word "apply" in exactly the same way, but they each seemed to mean something about using physics in a new context or in "real life". They further commented that this application helped them learn the material, so they did have something in common with the students who said that the laboratory help them understand physics.

Student 16 talked about applying physics as something that was only done in the laboratory, not in lecture:

If I can see the concepts then I learn it better than if someone just tells me that this works, I won't learn as well if I know how and why and if I see it working and apply the stuff, but someone has already told me that, it just makes a lot more sense. The entire process is better than just being given equations and word problems and examples.

This student does not see "word problems and examples" as applications of physics, although his or 
her professor might. For this student, applying physics means seeing it working in the laboratory.

Student 13 used different words to say the same thing:

It helps, like I said before, take concepts and put them into different context, I think that from an education standpoint that is a good thing to do, take the material make it real in front of you. I think that makes sense to have that class. I hear a lot of people even at the end of class who say oh I understand this and this better.

For this student, it seems that physics is not "real" until it is in a situation that he or she can manipulate. Several students noted that they valued the laboratory because they got to work with their hands.

\section{Lab Gives Students Hands-On Experience}

Five students, $28 \%$ of those responding, said that the lab course is there to give them hands-on experience.

Student 5 likes laboratory more than lecture, at least in part, because laboratory is more active. The student said that laboratory was

... more like hands on, you don't just sit there and take notes, like what we talk about in lecture I can't like picture the concept really well, and then you can see like how it actually works and stuff in the lab.

This student's comment is closely related to that of the students in the previous section, but he or she leads with the phrase "hands on". Even in relatively small lecture courses, students are passive a good deal of the time. Student 3 echoes these sentiments and expands on them, saying that the reason we have laboratories is:

because during lecture you are just doing equations and you just plug those in like when you are working your problems and you are putting in numbers, but during the lab like you actually are like figuring out like what you know the mass of the object of it is by measuring its velocity at a certain point, and I think that is kind of cool, cause you know you can't really do that when you're, I mean you do that in a problem but here you're actually seeing it.

This student seems on the point of acknowledging that a professor might see physics problems as hands-on applications of physics concepts, but dismisses that with the last phrase, "but here you're actually seeing it." During lecture you "just do equations" and "just plug those in", but during the laboratory you "actually are ... figuring out ... by measuring."

Student 1 values the hands-on experience in laboratory because he or she thinks that's the way he or she learns best.

In my opinion the labs are because it gives people ... I mean some college students are very good and visualizing and can do just fine with the lecture alone. To me the labs are helpful because I am a hands-on person. I am not a very good student, you know as far as just taking something out of a textbook and being able to apply it. I need that on-the-job experience, hands-on experience to associate it with. So to me the lab is very good for that purpose.

This student seems to think that some students, perhaps the best students, can learn purely from lecture, but others need extra help. It is only with direct experience, manipulating things with his or her hands, that this student can learn and apply knowledge of physics.

\section{DISCUSSION}

The three broad categories of response to the question, "What do you think is the purpose of this laboratory course?" that were most popular were helping students understand, apply, and get hands-on experience with the material. These categories are closely related. When students apply the material they learned in lecture, or see it in a new context, they also understand it better. Similarly, the students who talked about valuing hands-on experience also spoke highly of it because they felt it helped them learn the physics concept they had been exposed to in their lecture course.

Nearly all of the student responses to the question, "what do you think is the purpose of this laboratory course?" correspond to the third goal listed by the AAPT, Conceptual Learning [5]. Students believe that the reason we require them to take the introductory laboratory course is to help them understand the material they learn in the lecture course by applying it and getting some hands-on experience with it.

It is notable that many of the students who contrasted the laboratory course with the lecture course either stated or implied that they had trouble understanding the material presented in lecture, had trouble applying the material to the real world, and did not have a chance to work with the material themselves. The faculty have been working hard to 
include lots of demonstrations in their lectures, and try hard to include discussion, peer learning, and problem solving during the lecture course when possible. These student results indicate that the faculty should examine how much active learning is actually taking place during the lecture course, and what it would mean for faculty and students to change to a format more like SCALE-UP [4].

As our department considers making changes to our introductory physics courses, we can take the time to discuss why we have been teaching the way we have, why our students have decided what they have about the purpose of the current course, and whether conceptual learning should be the main goal of our laboratory activities in the future.

\section{REFERENCES}

1. J. Jacob \& J. Blue. Reform of Introductory Laboratories: Baseline Data. Presented at the National Meeting of the AAPT, Anchorage, AK (2006)

2. J. Blue. One Laboratory Course Serving Two Populations: Student Perceptions of Their Understanding Of Physics. Presented at the PERC, Syracuse, NY (2006)

3. J. Blue \& M. Fisher. Adapting a Photoelectric Effect Lab for the First-Year Laboratory. Presented at the National Meeting of the AAPT, Chicago, IL. (2009)

4. http://scaleup.ncsu.edu/

5. AAPT. Goals of the Introductory Physics Laboratory. http://www.aapt.org/Policy/goaloflabs.cfm (1997)

6. http://www-rci.rutgers.edu/\%7eetkina/isle.htm 